\title{
Interactive comment on "Surprising absence of strong homonuclear coupling at low magnetic field explored by two-field NMR spectroscopy" by Ivan V. Zhukov et al.
}

\section{Gottfried Otting (Editor)}

gottfried.otting@anu.edu.au

Received and published: 19 August 2020

Dear Professors Ivanov and Ferrage,

thank you for submitting the revised version of your manuscript "Surprising absence of strong homonuclear coupling...". You have addressed all comments raised by the reviewers as well as the posted comment. There is a single point left: in early discussions of how MR should distinguish itself from conventional journals in the field of magnetic resonance, the founders of the journal (including Geoffrey) strongly felt that software that has been written specifically to underpin the results presented in an article shall be made generally available by deposition in an appropriate depository. This is in keeping

Printer-friendly version

Discussion paper 
with the spirit of quality, transparency and general impact. Therefore, an affirmation like "will be provided by the authors upon request" is not considered sufficient - please install your simulation program in a suitable depository and provide the access information in your final manuscript or as supporting information. We highly recommend NMRbox (administered by Jeff Hoch, who also is an editor of MR). In case you find it difficult to use NMRbox, Mehdi Mobli may be able to assist. In the manuscript, reference to the software is to be spelled out in a section entitled "Code availability".

Reading through your revised version, I found some very minor issues that you may wish to correct: The new sentence "Such effects of couplings to heteronuclei are of relevance for abundant nuclei (protons), whereas for other nuclei they become important when uniform spin labelling is used." got me quite confused (for me, spin labels are radicals used in EPR) - I would have found it clearer like this: "Such effects of couplings to heteronuclei are of relevance for abundant nuclei such as protons or $13 \mathrm{C}$ spins in uniformly 13C-labelled molecules." In line 151, shouldn't it read "omega3 $=\ldots$ delta3"? The shuttle times quoted in the legend of Fig. 2 differ from those in the main text. "REBURP" is spelled differently at different instances in the article. In line 260, I guess you mean "withstand" instead of "stand".

Thank you again for posting a fine article to Magnetic Resonance.

Best regards, Gottfried Otting

Interactive comment on Magn. Reson. Discuss., https://doi.org/10.5194/mr-2020-14, 2020. 